\title{
Research on the Development Strategy of Cross-border Electronic Commerce under the Strategic background of "Belt and Road Initiative"
}

\author{
Suzhen Yu, Xiaoli Huang, Juying Li, Wang $\mathrm{Li}^{*}$ \\ Nanchang Institute Of Science \&Technology, Jiangxi Nanchang, Chinese, 330108 \\ Jiangxi University of Applied Science, Jiangxi Nanchang, Chinese, 330100 \\ Jiangxi University of Applied Science, Jiangxi Nanchang, Chinese, 330100 \\ Jiangxi University of Traditional Chinese Medicine, Jiangxi Nanchang, Chinese, 330100 \\ *Correspondence author: wangli0550@163.com
}

\section{key words Belt and Road Initiative; Cross-border Electronic Commerce; Development Strategy}

\begin{abstract}
Under the constant development of "Internet +", the common development of e-commerce and traditional marketing. With the deepening of the "one-way" thought, the e-commerce transaction across the country is becoming more and more extensive, the proportion of its market is growing, and it plays a very important role in the investment and the transaction, and the "one-way" development strategy is the top priority of the country's production work. And realizes the opening of the resources and the sharing of information. Its contents include: the construction of the Silk Road on Electronic Commerce, the construction of new trade investment, the creation of a new marketing mode, the construction of the development of ecological civilization, and the promotion and development of the one-way strategy The exhibition will make cross-border e-commerce widely used.
\end{abstract}

Topic: the application of CO-OP mode in the training of cross border e-commerce talents under the perspective of "one belt and one road", Item number: GL17118.

\section{Introduction}

As one of the most important platforms for foreign trade exchanges in ancient China, the Silk Road has been well inherited and further developed by the "Belt and Road Initiative" strategy. Like the Silk Road thousands of years ago, Belt and Road Initiative will continue to cooperate and exchange with many countries, promote each other, develop in coordination with each other, and further enhance diplomatic relations between countries and regions. At the same time, with the development of the times, the Internet technology has been developed rapidly, and the cross-border e-commerce based on the Internet has also been able to grow rapidly under the background of economic globalization. As the product of Internet and economy, how to carry out "one belt and one" in our country? Under the background of road strategy and globalization, the development of electronic commerce will play a very important role in the development of China's economy.

\section{Cross-border e-commerce and "Belt and Road Initiative" strategy}

\subsection{The concept of Cross-border Electronic Commerce}

The so-called cross-border e-commerce refers to the foreign trade transactions carried out in different countries. The way of transaction and payment is realized through the electronic commerce platform. An international business exchange that sends goods or services through cross-border logistics is mainly through the network to carry out transactions, with e-commerce as the mode. Under the development of electronic commerce, the traditional international trade mode has been innovated, which makes the economy tend to be integrated, trade gradually developed into globalization, the competition of brands has been greatly enhanced, the sales channels are more 
extensive, and it occupies a more important position in the international market.

\subsubsection{Cross-border e-commerce accelerates the pace}

the electronic commerce platform plays a great role in the utilization of the consumers and the sellers, can avoid many intermediate links, directly sell the goods to the customers, or directly sell to the overseas, and the steps are greatly reduced, the scope and the objects are expanded, so that the trade is more simple and convenient, On the other hand, the cost of the product is also greatly reduced, the threshold is correspondingly reduced, the round-trip speed of the funds is improved, and the transmission of information is faster. With the development of cross-border e-commerce, global trade will be further affected, both in terms of human, financial and social resources, and in the international market It has been greatly developed and utilized, and the import and export trade has also been expanded, which can produce more value.

\subsubsection{The strong development of "made in China" will provide sufficient impetus}

Although our country is known as the world's factory, in general, the role played by many enterprises is just a place for processing. However, the development of cross-border e-commerce provides them with a better platform, and realizes the interface between the consumer and the enterprise, so that many problems which are difficult to be solved by the quality problem are effectively solved, and the advantages of the manufacturing are fully utilized, To create our own brand, to create and inject new vitality into China. So, for many small and medium-sized enterprises in our country, cross-border e-commerce has provided a new industrial chain for them, and its trade pattern has been transformed, making it far more beautiful Young, so let the "Made in China" really transform to the "China's creation".

\subsubsection{Give full play to its driving force}

Advanced communication systems and technology applications provide a guarantee for cross-border e-commerce, make the relationship between producers, consumers and sellers closer, but also provide more thoughtful, multi-level services, so that many limitations of traditional trade have been broken, have been better developed, make the speed of information flow faster, and the communication between countries has been realized on the basis of the Internet. In international trade, cross-border e-commerce provides it with sufficient motive force, which makes many resources be better utilized as a whole, and truly realizes a win-win situation, which greatly increases China's foreign transactions, optimizes its structure and obtains the industrial chain. This has led to closer and more coordinated linkages between the various sectors.

\subsection{The Development of "Belt and Road Initiative" Strategic thought on Cross-border Electronic Commerce}

\subsubsection{Eliminate the limitations of the transaction}

With the implementation of "Belt and Road Initiative" strategy, many transaction restrictions under the traditional mode have been broken. The construction of "Belt and Road Initiative" is the basis for the realization of only negotiations between countries. At the same time, it is also necessary to improve the relevant legal systems and policies, so that the orderly development of the Internet in our country under the correct guidance, so that the economic model of our country can be successfully transformed, and points out the correct way forward for the development of traditional enterprises in our country.

\subsection{2 such that the related services are optimized}

Under the leadership of "Belt and Road Initiative", the enterprise identification mechanism will be widely implemented throughout the country, so that e-sports port will be further developed, the cross-border logistics service industry will be strengthened, and electronic payment will become more and more popular and simple. The classified management will be adjusted so that the quality of service can be continuously strengthened and the service function of customs can be better brought into play.

\subsubsection{The rapid development of cross-border logistics}

There are many large-scale enterprises in China, which are gradually expanding the market overseas, but because of the relatively complicated nature, it is difficult to realize the overall adjustment of 
the market. Under the leadership of the "One Belt and One Road" strategy, many related policies are introduced under the management of the State, so that the process is more reasonable, the service is more perfect, the domestic construction of more storage bases is promoted, and the service and communication with the international large-scale logistics are strengthened, So that the distribution efficiency is greatly improved.

\section{Formulating the Development Mode of Cross-border Electronic Commerce under the Strategy of "Belt and Road Initiative"}

To realize China, we need to transform the traditional economic model, inject new vitality, provide a new way of thinking, and actively build an e-commerce platform. In order to realize the orderly reconciliation of domestic and foreign markets, we need to study the relevant technologies, issue relevant policies, formulate corresponding laws, build a number of multinational enterprises belonging to China, and enhance their competitiveness in the international market. At the same time, brand awareness also needs to be valued. Enterprises want to take advantage of the transformation and upgrading, brand strategy must be effectively implemented. So that the past imitation of the product phenomenon has been changed, product innovation and change, diversity and. High quality, with the most sincere service attitude, make the domestic and foreign consumers more favor, make China make a real move to China to create. The effective utilization of large data can provide guarantee for cross-border e-commerce. On the one hand, the platform can analyze and integrate many overseas data, find the customer, find the way to sell, can also develop more targeted products and services according to different tastes of different people, and greatly improve our competition level; on the other hand, the service quality of the "Cloud Marketing" is improved, The analysis of the information of the resources makes it possible for business change to proceed more effectively.

\section{Conclusion:}

Cross-border e-commerce must be a trend. Under the continuous development of Internet, e-commerce and traditional marketing develop together. With the deepening of Belt and Road Initiative's thought, e-commerce transactions across the border are becoming more and more extensive, and the proportion of the market is also growing, which plays an important role in investment and trading. Under the development and guidance of "Belt and Road Initiative" strategic thought, the channels of cross-border e-commerce have been more diversified, and the production capacity among countries along the way of "Belt and Road Initiative" has been greatly improved, resources have been widely used, and information technology has been shared.

\section{References:}

[1] Preliminary study on the construction of business foreign language teaching staff in the background of "One Belt and One Road" 's strategy[J]. Ding Jinzhu. Science and technology economic guide. 2019 (25)

[2] Opportunities and Challenges of Guangxi Foreign Trade in the Context of "Belt and Road" Strategy [J]. Liu Guobi. Contemporary Economy.2017(29).

[3] The opportunity and development path of business English teaching in the background of "One Belt and One Road" 's strategy[J]. Wang Zhongwei. A house of drama. 2018 (09)

[4] Analysis of the demand for professional talents in the context of the "One Belt and One Road" strategy[J]. Dong Yanhui. The management and technology of small and medium-sized enterprises (medium-sized periodical). 2015 (10)

[5] A probe into the training Model of Business English Professionals under the Strategic background of Belt and Road Initiative [J]. Sudan. Chinese Journal of Multimedia and Network Teaching (first ten days). 2019 (03) 
[6] A probe into the training Model of Business English Professionals under the Strategic background of Belt and Road Initiative [J]. Wang Zhuo, Tao Ke. Journal of Heilongjiang Institute of Technology (comprehensive edition). 2017 (12)

[7] A brief analysis of the opportunities and challenges of China's foreign trade under the strategic background of Belt and Road Initiative [J]. Lu Zhejiang Yu. Economic and trade practice. 2018 (02)

[8] A study on the foreign trade of corn industry in Jilin Province under the strategic background of Belt and Road Initiative [J]. Zhu Weixuan, Tan Tao, Liu Liqin. Forum on Industry and Science and Technology. 2017 (19)

[9] Analysis of foreign trade logistics of agricultural products in Yunnan and Vietnam under the strategic background of Belt and Road Initiative [J]. Zeng Qiumei, Zhang Yiwei, Wang Yan. Logistics technology. 2015 (23)

[10] The situation analysis of the development of Yunnan's electronic commerce under the background of "bridgehead" 's strategy[J]. Sun Liangtao. China's commerce. 2012 (03) 